\begin{tabular}{|c|l|}
\hline Title & Failure Mechanism of Empty and Concrete Filled CFRP Box Beams \\
\hline Author(s) & Gautam, Bishnu Prasad; Matsumoto, Takashi \\
\hline Citation & $\begin{array}{l}\text { Journal of Composites for Construction, 14(3), 336-345 } \\
\text { https://doi.org/10.1061/AASCE)CC.1943-5614.0000089 }\end{array}$ \\
\hline Issue Date & 2010-05 \\
\hline Doc URL & http://hdl.handle.net/2115/45418 \\
\hline Type & article(author version) \\
\hline File Information & JCC143_336-345.pdf \\
\hline
\end{tabular}

Instructions for use 


\title{
Failure mechanism of empty and concrete-filled CFRP box beams
}

\author{
Bishnu Prasad Gautam $^{1}$ and Takashi Matsumoto ${ }^{2}$
}

\section{Abstract}

This paper highlights the failure mechanism of beams composed of carbon fiber reinforced polymer (CFRP) box with and without infill concrete, and subjected to four point bending and axial load. In an experimental study performed with twenty small scale beams from five types of CFRP laminates, the beams failed near a loading plate. This study employs finite element analysis to investigate the failure mechanism. Concrete is modeled as an isotropic material capable of cracking in tension and crushing in compression. CFRP is modeled as an orthotropic material with linear constitutive relation, and Tsai-Wu failure criterion is employed for CFRP. The analysis reproduces the observed beam failure. Local bending of top flange governs the failure of empty beams. CFRP failure near loading plate governs the failure of filled beams. Failure of CFRP occurs with more than $60 \%$ contribution by longitudinal compressive stress and the rest by in-plane shear stress. The contribution of the longitudinal compression increases with an increase in axial load. Moreover, the beams with more fibers in the transverse direction fail by longitudinal compression.

\section{CE Database subject headings}

Carbon fiber reinforced polymer (CFRP); concrete; box beam; failure

\footnotetext{
${ }^{1}$ Corresponding author. M.E., Department of Civil Engineering, University of Tokyo, Japan. Present address: Butwal Power Company Ltd., Ganga Devi Marga 313, P.O. Box 11728, Kathmandu, Nepal. Tel.: +977 14785295; e-mail: bgautam@gmail.com

${ }^{2}$ Ph.D., Associate Professor, Graduate School of Engineering, Hokkaido University, Kita 13, Nishi 8, Kita-ku, Sapporo 060-8628, Japan. E-mail: takashim@eng.hokudai.ac.jp
} 


\section{Introduction}

Composite structure made of concrete encased with fiber reinforced polymer (FRP) emerges as a viable structure for beam applications. FRP-concrete hybrid beam was first proposed by Fardis and Khalili (1981) as a concrete beam encased with FRP sheets. Thereafter, many studies have dealt with the use of Glass FRP (GFRP) in conjunction with concrete for beam applications. A popular application has evolved in the form of concrete-filled GFRP tube (CFFT). Mirmiran and Shahawy (1995) studied a CFFT box beam as an alternative to an RC beam-column. The FRP tube acts as a stay-in-place formwork for fresh concrete, and as a confining medium for hardened concrete. This leads to the reduction of formwork and labor cost, and accelerates construction process. However, relatively low strength and low stiffness of GFRP remain as limitations for beam applications requiring high strength and low deflection.

Carbon FRP (CFRP) has evolved as a high performance material with longitudinal tensile strength and elastic modulus comparable to those of steel, and at the same time with low specific gravity of about 1.6 (Mallick 1993). A hybrid concrete-CFRP beam is conceptualized to take advantage of this high performance material. The beam is envisaged as a modular unit for a large scale civil infrastructure application where a slim but strong beam section is necessary (Gautam 2007). The hybrid beam consists of a CFRP box filled with plain concrete and will act under transverse and axial load. The arrangement of the modular unit is novel, and its details remain proprietary. The novel concrete-filled CFRP box beam needs an understanding of damage and failure mechanism before it can be realized in a practical application.

Few studies on concrete-FRP composite beams have focused on failure mechanism. A study by Hayes and Lesko (2007) presents failure analysis of an empty FRP box beam. The study involves finite element analysis of the beam tested in an experimental program. The beam was composed of GFRP with some layers of CFRP attached at the flange. In the experiment, the beam failed at the top flange near a loading plate. Maximum stress failure criterion was employed in the finite element analysis, but only at the topmost CFRP lamina and only for compressive stress. The top flange failure was concluded as the 
compression failure of carbon plies. However, the input strength of a CFRP lamina which is termed as “relatively low” is not directly measured, and appears very low compared to those of typical CFRP laminas.

A similar location of failure i.e. near a loading plate is observed in a FRP encased concrete beam studied by Fardis and Khalili (1981). Similarly, a beam column structure made of a CFFT box filled with concrete shows a similar failure location near loading plate (Mirmiran et al. 1999).

A recent paper by Gautam and Matsumoto (2008) describes about the interface and shear behavior of the newly proposed concrete-filled CFRP box beams. The beams suffered from interface slippage and resulted in high shear deformation of CFRP at web locations. However, the beam failure mechanism is not explained. Matsumoto et al. (2007) discuss the failure mechanism, but limited to only one concrete-filled CFRP box beam. It is imperative to clarify the failure of the newly proposed concretefilled CFRP box beams. This study is devoted to the study of the failure mechanism by simulating with finite element analysis the failure of the empty and concrete-filled beams tested in an experiment.

\section{Experimental program and beam specimens}

Twenty beams were tested under four point bending and axial load in an experimental program. Five types of CFRP laminates were utilized by varying the ratio of fiber volume proportion in the longitudinal to transverse direction of a beam. The designations of the laminates are shown in Table 1. A CFRP laminate L9T1, for instance, means the ratio of fibers in the longitudinal (L) to transverse (T) directions as 9:1. Out of the twenty beams, four beams are empty (E), and sixteen beams are concretefilled (F). Fig. 1 shows a photograph of an empty box beam. The box is composed of $5 \mathrm{~mm}$ thick crossply CFRP laminate. The geometry and loading of the beams are shown in Fig. 2. The beams in this study are small scale beams with size less than that of typical beams. Depending upon the ratio of mid span bending moment $(\mathrm{kN}-\mathrm{m})$ to axial load $(\mathrm{kN})$, filled beams are classified as F- $\infty, \mathrm{F}-32, \mathrm{~F}-16$ and F-04 with the ratios as $\infty, 0.32,0.16$ and 0.04 respectively. The ratio was maintained constant during the entire range of loading for a beam. 
In the experiment, all the beams were tested under four point bending and axial load. They failed suddenly without having any prior indication of failure. Thus, the experiment could hardly capture the initiation and propagation of failure. Fig. 3 shows the typical failure snapshot of the beams in the experiment. The failure location in most of the beams was observed near a loading plate. Particularly, failure initiation in L9T1-L1T1 beams appeared at the web while that in L1T2 and L1T9 beams appeared at the corner locations on the top flange. Later, a finite element analysis (FEA) was employed to investigate the beam failure.

\section{Finite element analysis (FEA)}

General purpose FEA software, Marc, was utilized for the analysis of the empty and concretefilled CFRP box beams. Marc can perform linear and nonlinear stress analysis for static and dynamic problems (MSC.Software 2001). A graphical user interface called Mentat was utilized for pre and post processing. Only one quarter of a beam was modeled taking advantage of the symmetry in two mutually perpendicular vertical planes. 8-node 3D solid elements with tri-linear interpolation were utilized both for concrete and CFRP.

Gautam and Matsumoto (2008) have shown that the concrete-filled CFRP box beams as considered in this study suffer from interface slippage between concrete and CFRP, and that the beams should be modeled to incorporate the slippage. All the beams were, therefore, modeled as a contact problem that simulated the frictional slip at the interface. A contact analysis possesses a provision for slip, thereby allowing to simulate the slip between concrete and CFRP without collapsing into a trivial solution. Separate nodes were assigned for concrete and CFRP at the same location to achieve this condition. Interface friction was also considered in the contact analysis. The friction coefficient was taken as 0.4 (Gautam and Matsumoto 2008). 


\section{Failure analysis}

Failure of CFRP was analyzed using Tsai-Wu failure criterion. This is one of the most widely used criteria in the field of fiber reinforced composites. The criterion accounts for interaction among stresses, and takes account of different material axis symmetries, multi-dimensional space and multi-axial stresses (Tsai and $\mathrm{Wu}$ 1971). It assumes that a failure surface exists in stress-space, which, for an orthotropic material loaded along material principal directions, can be expressed as

$$
\begin{aligned}
& F_{1} \sigma_{1}+F_{2} \sigma_{2}+F_{3} \sigma_{3}+F_{11} \sigma_{1}{ }^{2}+F_{22} \sigma_{2}{ }^{2}+F_{33} \sigma_{3}{ }^{2} \\
& +2 F_{12} \sigma_{1} \sigma_{2}+2 F_{23} \sigma_{2} \sigma_{3}+2 F_{13} \sigma_{3} \sigma_{1}+F_{44} \tau_{23}{ }^{2}+F_{55} \tau_{13}{ }^{2}+F_{66} \tau_{12}{ }^{2}=1
\end{aligned}
$$

where $F_{i}$ and $F_{i j}$ with $i, j=1,2, \ldots, 6$ are given as

$$
\begin{aligned}
& F_{i}=\frac{1}{\sigma_{i}^{T}}+\frac{1}{\sigma_{i}^{C}}, \text { for } i=1,2,3 ; \\
& F_{i i}=-\frac{1}{\sigma_{i}^{T} \sigma_{i}^{C}}, \text { for } i=1,2,3 ;
\end{aligned}
$$

$$
\left.\begin{array}{l}
F_{44}=\frac{1}{\left(\tau_{23}^{F}\right)^{2}} \\
F_{55}=\frac{1}{\left(\tau_{13}^{F}\right)^{2}} \\
F_{66}=\frac{1}{\left(\tau_{12}^{F}\right)^{2}}
\end{array}\right\}
$$

$F_{12}, F_{23}$ and $F_{13}$ are strength interaction parameters. $F_{12}$ can be calculated (Mallick 1993) as

$$
-0.5 \sqrt{F_{11} F_{22}} \leq F_{12} \leq 0
$$


$F_{23}$ and $F_{13}$ could also be calculated in a similar manner. Notations $\sigma_{i}$ and $\tau_{i j}$ for $i, j=1,2,3$ are the stress tensors. With superscripts “T”, “C” and "F”, tensor notations also indicate the strength in tension, compression and shear respectively.

Material failure was checked by applying the criterion of (1) at every integration point of a finite element. If the criterion was satisfied, the material at that location was considered as failed. Failure was indicated in the form of a failure index expressed in percentage.

\section{Material properties and modeling}

\section{Concrete and confinement effect}

The material model chosen for concrete is capable of cracking and crushing. Concrete was modeled as linearly elastic in tension up to cracking and, then, tension softening to a strain of 5000 micron. Concrete properties are shown in Table 2. Elastic modulus, Poisson's ratio and compressive strength were obtained from a concrete test. Tensile strength $\left(f_{t}\right)$ was calculated as the rupture stress (ACI 318-95 1999) as

$$
f_{t}=0.53 \sqrt{f_{c}^{\prime}}
$$

where $f_{c}^{\prime}$ is the compressive strength of unconfined concrete.

A bi-linear confinement model of concrete proposed by Samaan et al. (1998) was utilized in this analysis for concrete in compression. The model is applicable to simulate the concrete inside a CFRP box beam (Gautam 2007). This model, unlike many other confinement models, considers the hoop stiffness of CFRP and is given as

$$
f_{c}=\frac{\left(E_{c}-E_{2}\right) \varepsilon_{c}}{\left[1+\left(\frac{\left(E_{c}-E_{2}\right) \varepsilon_{c}}{f_{0}}\right)^{n}\right]^{1 / n}}+E_{2} \varepsilon_{c}
$$


where $f_{c}, \varepsilon_{c}$ are the compressive stress and strain of concrete, respectively; $E_{c}, E_{2}$ are the first and second slopes of a bilinear model, respectively; $n$ is the curve-shaped parameter $(=1.5)$ and $f_{0}$ is the reference plastic stress. $E_{2}$ and $f_{0}$, in MPa unit, are respectively given as

$$
E_{2}=245.61\left(f_{c}^{\prime}\right)^{0.2}+1.3456 \frac{E_{j} t_{j}}{D}
$$

and

$$
f_{0}=0.872 f_{c}^{\prime}+0.371 f_{r}+6.258
$$

where $f_{r}$ is the confinement pressure given as follows

$$
f_{r}=\frac{2 f_{j} t_{j}}{D}
$$

Here, $E_{j}, t_{j}, D$, and $f_{j}$ are respectively the hoop-directional extensional modulus of CFRP, thickness of a CFRP box, inside dimension of the box, and hoop strength of the CFRP.

\section{CFRP}

This study considered the CFRP laminate as a 3D orthotropic material with linear elastic behavior. This approach accounts for the through thickness normal stress and interlaminar shear stresses, and is useful for a thick cross-ply laminate. The laminate lay up is proprietary. The fabrication process involved the use of a unidirectional CFRP prepreg. The constituents of the prepreg were $121.1^{\circ} \mathrm{C}\left(250{ }^{\circ} \mathrm{F}\right)$ curable epoxy and T700S carbon fiber.

While the fabrication process and fiber volume fraction for all the laminates could be same, different ratios of fiber volume were maintained in two principal directions by suitably arranging the prepregs in either parallel or perpendicular to each other. As a material, there were three types of CFRP 
laminates with fiber volume proportion in two perpendicular directions as 9:1, 2:1 and 1:1. These three laminates were utilized to construct five types of box beams with their major fiber direction along either the longitudinal or the transverse direction of a beam. Hence, this study dealt with five types of CFRP box beams with fiber volume proportion in the longitudinal to the transverse direction of the beams as 9:1, 2:1, 1:1, $1: 2$ and 1:9.

CFRP was modeled as a linearly elastic orthotropic material up to failure. The material library for an orthotropic material was utilized to input nine independent mechanical properties in three mutually perpendicular directions. In-plane properties were obtained from coupon test of CFRP laminates. Sheet laminates were prepared for the three types of CFRP. Lay up and fabrication process were kept same as in box beams. Coupons were prepared from the sheets. The coupon test is hereafter referred to as sheet coupon test. Afterward, coupons were extracted from the visually intact portion of tested empty box beams. Tests on these coupons provided tensile strength and modulus of the CFRP laminates actually used in the box beams. This coupon test is hereafter referred to as box coupon test. Each property referred from the coupon tests was obtained as an average of 5 tests. Additionally, in-plane shear strength was assumed by referring to Mallick (1993) for high modulus and strength (HMS) carbon-epoxy unidirectional composite. In-plane material properties for all five types of CFRP are shown in Table 3. On the other hand, out-of-plane properties were suitably assumed from different literatures and are presented in Table 4.

\section{Results}

This section presents the results from the finite element analysis for the four empty and sixteen concrete-filled CFRP box beams. Fig. 4 shows the failure of the empty L1T1 beam. The gray scale bands in the figure indicate failure index distribution as calculated by Tsai-Wu criterion. Failure occurred at the top flange near a loading plate. In general, empty beams failed at the top flange on the vicinity of a loading plate. 
The damage and failure of the concrete-filled beams in the finite element analysis could be traced in detail unlike in the case of the experiment. Damage details of the beams in the analysis are illustrated with a typical load-deflection curve [Fig. 5] and typical damage snapshots. Fig. 6(a) shows the initiation of damage in the form of concrete cracking at an early stage of loading. However, concrete cracking is not severe even at the ultimate failure of the beam as in Fig. 6(b). Fig. 7 shows the concrete compressive strain distribution at different stages of loading. Failure location and pattern of failure are shown in Fig. 8 and Fig. 9. Specifically, failure in L9T1, L2T1 and L1T1 beams initiated at the web part just below a loading plate, and that in L1T2 and L1T9 beams initiated at the corners of the top flange on either side of a loading plate. The damage sequence of the concrete-filled beams can be basically summarized as-

Stage 1: $\quad$ Concrete cracking in tension initiated at the early stage of loading. This condition occurred at a load less than $10 \%$ of the load at which ultimate failure of a beam would have occurred. Concrete crack started, without any exception, at the lower part of a beam just along the transverse load axis [Fig. 6(a)]. Cracking of concrete was suppressed until relatively higher load in the case of highly axial loaded beams.

Stage 2: $\quad$ Concrete crack grew gradually in extent and number. Compressive strain in concrete increased to a strain level of 2000 micron $(0.002 \mathrm{~mm} / \mathrm{mm})$ which is equivalent to the typical peak unconfined compressive strain of concrete [Fig. 7(a)]. This condition mostly occurred at 35 to $55 \%$ of the load at which ultimate failure of the beam would have occurred. CFRP was intact at this stage.

Stage 3: $\quad$ Concrete cracking continued to extend on the lower half of a beam approximately within the middle third of a beam span. Compressive strain in concrete in the upper part of the beam also grew in magnitude and extent. In the meantime, CFRP failure just initiated at one or few nodes. This condition occurred at a load equal to about 80 to 100\% of the ultimate load. Failure in L9T1-L1T1 beams initiated mostly at web just below a loading plate as seen in Fig. 8(a). Similarly, failure in L1T2 and L1T9 beams initiated at web-flange junction on either side of a loading plate as seen in Fig. 9(a). 
Stage 4: $\quad$ With further increase in load, compressive strain in concrete reached as high as 15000 micron as seen in Fig. 7(b). CFRP failure was observed at many nodes at web and top flange locations. Beam stiffness changed abruptly [Fig. 5]. The fourth stage could be approximated as the ultimate failure of the beams. The failure location of L9T1-L1T1 beams in the analysis was observed at the web near a loading plate [Fig. 8(b)]. Similarly, the failure of L1T2 and L1T9 beams mostly took place at the corner location of the top flange [Fig. 9(b)]. Final failure of the beams was observed in the upper portion near a loading plate. It is noted that the failure location was observed in coherence with the experiment [Fig. 3].

\section{Discussions}

\section{Empty beams}

Most notable to the empty beams was the local bending of top flange on the vicinity of a loading plate. This produced longitudinal tensile stress on the bottom side of the top flange just below a loading plate. An analysis was performed to confirm the stress condition with 4-element through the flange thickness. Tensile stress of more than $100 \mathrm{MPa}$ occurred at a load of $47.5 \mathrm{kN}$ for L1T1-E beam as shown in Fig. 10. Additionally, compressive stress distribution along the flange thickness was highly nonuniform. Thus, the maximum longitudinal compressive stress in the beams was observed not at the mid span but at the upper portion of the top flange in the vicinity of a loading plate. Consequently, the location became a consistently critical location for failure. The local bending of the top flange governed the failure of the empty CFRP box beams. Local bending of the top flange could have governed the failure of the empty FRP box beam which Hayes and Lesko (2007) reported to fail in the compression flange near a loading plate.

\section{Concrete-filled beams}

Damage pattern and progress were observed similar for all the concrete-filled beams. Concrete cracking occurred at very early stage [Fig. 6(a)] but it was not severe until the ultimate failure [Fig. 6(b)]. 
Concrete crushing in compression did not happen. Also, no tensile failure of CFRP was noticed. CFRP failure was observed in compression region in all the beams.

With the longitudinal direction (direction 1) of the CFRP laminates along the longitudinal axis of the beams, L9T1-L1T1 beams possess very high extensional modulus and compressive strength along the longitudinal axis compared to that of L1T2 and L1T9 beams [Table 3]. Likewise the observed failure initiation locations in the L9T1-L1T1 series and the L1T2-L1T9 series are different. Therefore, it is customary to discuss the failure of the concrete-filled beams under two streams as L9T1-L1T1 beams and L1T2-L1T9 beams.

Failure in the L9T1-L1T1 beams initiated at the web just below a loading plate. Failure contribution of each stress component was calculated by Tsai-Wu criterion for selected nodes at the failure initiation location of CFRP. The contributions of stresses other than the longitudinal compression and the in-plane shear were negligible. Thus, Tsai-Wu failure envelope for the beams was plotted against the longitudinal compressive stress and the in-plane shear stress keeping all other stresses as zero. Fig. 11 to Fig. 13 show the failure envelope for the beams along with the two stresses at the selected nodes of the web where the failure was just initiated.

The interface between concrete and CFRP suffers from slippage and the concrete contributes very little to transfer shear load (Gautam and Matsumoto 2008). Thus, the web of a CFRP box became the primary location to be acted by almost total shear load [Fig. 14]. Conversely, CFRP laminates in this study are cross-ply laminates and possess very low shear strength which is less than one-seventh of the corresponding longitudinal compressive strength. Similarly, CFRP laminates are significantly weaker in longitudinal compression than in tension. Therefore, a combination of high shear stress with high compressive stress became possible in the web just near a loading plate as can be seen in Fig. 14 and Fig. 15. Hence, failure of CFRP mostly occurred by a combination of longitudinal compression and in-plane shear stress [Fig. 11 to Fig. 13]. Contribution of longitudinal compressive stress to the failure was from about $60 \%$ for the beams without axial load to about $80 \%$ for the highly axially loaded beams. In-plane 
shear stress contributed about $40 \%$ to $20 \%$ to the failure of the concrete-filled L9T1-L1T1 beams. Even though the beams failed in the compression region, the longitudinal compressive strength of CFRP laminates was not fully utilized.

Immediately after the web failure of the L9T1-L1T1 beams, the top portion of the web released a significant portion of compressive load. Consequently, the top flange became the ultimate location to fail before the beam would finally fail to carry further load. Even before web failure, it was common to observe compressive stress in the top flange similar or more near loading plate than at the mid span as shown in Fig. 15. The observation of a series of beams shows that the top flange failure followed the web failure. Stress release in the experiment should have been sudden unlike in the analysis, thus the damage appeared suddenly in the experiment.

Failure in the L1T2-L1T9 beams initiated at the corners of the top flange near a loading plate. Tsai-Wu failure envelope for the beams was plotted against the longitudinal compressive stress and the in-plane shear stress keeping all other stresses as zero. Fig. 16 and Fig. 17 show the failure envelope for the beams along with the two stresses at the selected nodes of the flange where the failure was just initiated. While in-plane shear strength is same for all the beams, longitudinal compressive strength of L1T1-L1T2 beams is less than 50\% compared to that of L9T1-L1T1 beams. Therefore, L1T2 and L1T9 beams failed mostly in longitudinal compression. The effect of axial load was not pronounced in the failure mechanism.

\section{Conclusions}

This study investigated the failure mechanism of four empty and sixteen concrete-filled CFRP box beams of an experimental study by simulating with finite element analysis. Five types of CFRP laminates, L9T1, L2T1, L1T1, L1T2 and L1T9, were utilized with the ratio of fiber volume proportion in the longitudinal to transverse direction of a beam as 9:1, 2:1, 1:1, 1:2 and 1:9 respectively. Four types of filled beams were considered depending upon the axial load. All beams in the experiment failed near loading plate when tested under four point bending. An FE analysis was performed to investigate the 
damage and failure mechanisms. Concrete was modeled as an isotropic material capable of crushing and cracking. A confinement model was applied for concrete in compression. CFRP was modeled as an orthotropic material. Failure analysis was performed using Tsai-Wu failure theory. The interface between concrete and CFRP was modeled as a contact problem with capability of slippage. A failure location similar to that in the experiment was observed in the numerical study.

The empty beams suffered from local bending of top flange and showed compression failure near a loading plate. In the case of filled beams, the initiation of damage was in the form of concrete cracking in the lower portion of the beams near load application sections. The beams failed with the failure of CFRP on and near the top flange. Failure was initiated at the web location just below a loading plate in the L9T1, L2T1 and L1T1 beams having longitudinal direction of CFRP along the longitudinal axis of the beams. Longitudinal compressive stress contributed from about $60 \%$ to the failure of the beams having no axial load to about $80 \%$ to the failure of the highly axially loaded beams. The shear strength of CFRP laminates in these beams is less than one-seventh of the corresponding longitudinal compressive strength. Consequently, in-plane shear stress contributed about $40 \%$ to $20 \%$ to the failure of the concrete-filled L9T1-L1T1 beams. Failure in the L1T2 and L1T9 beams initiated at the corners of the top flange near a loading plate. These beams are weaker in longitudinal compression with compressive strength less than $50 \%$ of that of the L9T1-L1T1 beams. Failure in these beams occurred by longitudinal compression irrespective of the axial load.

The concrete-CFRP composite beams presented in this paper have been conceptualized for a large scale infrastructure application to work as modular units. The size of the beams in this study is less than that of typical beams. Additional research is needed to evaluate scalability of the methodology and results presented in this paper.

\section{Acknowledgements}

This work is part of a collaborated study project between the University of Tokyo, and joint researchers -Shimizu Corporation and Toray Industries, Incorporated. The authors acknowledge Shimizu 
Corporation, Japan and Toray Industries, Incorporated, Japan for granting permission to use experimental data and for their support in undertaking this study. The opinions expressed here are those of authors and not necessarily those of Shimizu Corporation and Toray Industries, Incorporated.

\section{References}

ACI 318-95 (1999). Building code requirements for structural concrete (318-95) and commentary (318R95). ACI.

Fardis, M.N., and Khalili, H.H. (1981). “Concrete encased in fiberglass-reinforced plastic.” ACI Journal, 78(6), 440-446.

Gautam, B.P. (2007). "Finite element analysis on deformation, damage and failure mechanisms of concrete-filled CFRP box beam under transverse and axial loads.” MS Thesis, the University of Tokyo, Japan.

Gautam, B.P., and Matsumoto. T. (2008). "Shear deformation and interface behaviour of concrete-filled CFRP box beams”. Composite Structures, 89(1), 20-27.

Hayes, M.D., and Lesko, J.J. (2007). "Failure analysis of a hybrid composite structural beam." Composites Part A: Applied Science and Manufacturing, 38(3), 691-698.

Hyer, M.W. (1998). Stress analysis of fiber-reinforced composite materials. WCB/McGraw-Hill, USA.

Mallick, P.K. (1993). Fiber reinforced composites: materials, manufacturing and design, 2nd Ed. Marcel Dekker Inc., New York.

Matsumoto, T., Gautam, B.P., Goto, S., Ishizuka, Y., Inada, H., Yoshitake, K., Sugiyama, H., Suzukawa, K., and Matsui, T. (2007). "Shear behavior of concrete-filled CFRP box beam.” In: Proceedings of the $62^{\text {nd }}$ JSCE Annual Meeting, Hiroshima, 12-14 September. p. 491-492 (CD ROM).

Mirmiran, A., and Shahawy, M. (1995). “A novel FRP-concrete composite construction for the infrastructure.” In: Proceedings of Structural Congress XIII, ASCE, USA, p.1663-1666.

Mirmiran, A., Shahawy, M., and Samaan, M. (1999). "Strength and ductility of hybrid FRP-concrete beam-columns.” J. Struct. Eng., 125(10), 1085-1093. 
MSC.Software (2001). MSC.Marc Volume A: Theory and user information, version 2001. MSC.Software Corporation, USA.

Samaan, M., Mirmiran, A., Shahawy, M. (1998). "Model of concrete confined by fiber composites.” J. Struct. Eng., 124(9), 1025-1031.

Toray (2007). "Functional and composite properties." <http://www.torayca.com/techref/index.html> (Jan. 15, 2007).

Tsai, S. W., and Wu, E. M. (1971). “A general theory of strength for anisotropic materials.” J. Compos. Mater., 5(1), 58-80. 
Fig. 1: An empty CFRP box beam

Fig. 2: Longitudinal and cross-section of a concrete-filled CFRP box beam

Fig. 3: Failure of a beam in the experiment. Failure occurred near loading plate away from mid span

Fig. 4: CFRP failure index (\%) in L1T1-E beam: (a) Failure initiation; (b) Ultimate failure

Fig. 5: Load-deflection curves for L9T1-F-16 beam

Fig. 6: Concrete cracking strain (mm/mm) in L9T1-F-16 beam: (a) Stage 1 (Load 9 kN)- concrete cracking starts; (b) Stage $4($ Load $111.1 \mathrm{kN})$ - concrete crack is still not severe

Fig. 7: Concrete compressive strain ( $\mathrm{mm} / \mathrm{mm})$ in L9T1-F-16 beam: (a) Stage 2 (Load $46.3 \mathrm{kN})$ concrete compressive strain reaches $2000 \mu$; (b) Stage 4 (Load $111.1 \mathrm{kN})$ - compressive strain in concrete is considerable

Fig. 8: CFRP failure index (\%) in L9T1-F-16 beam: (a) Stage 3 (Load 103.9 kN)- CFRP failure starts; (b) Stage 4 (Load $111.1 \mathrm{kN}$ )- significant CFRP failure takes place

Fig. 9: CFRP failure index (\%) in L1T9-F-04 beam: (a) Stage 3 (Load 52.5 kN)- CFRP failure starts; (b) Stage 4 (Load $62.5 \mathrm{kN}$ )- significant CFRP failure takes place

Fig. 10: Longitudinal tensile stress at top flange in L1T1-E beam (MPa)

Fig. 11: Stress state in the L9T1 beams before failure

Fig. 12: Stress state in the L2T1 beams before failure

Fig. 13: Stress state in the L1T1 beams before failure

Fig. 14: In-plane shear stress in L9T1-F-16 beam at 96.7 kN (MPa)

Fig. 15: Longitudinal compressive stress in L9T1-F-16 beam at 96.7 kN (MPa)

Fig. 16: Stress state in the L1T2 beams before failure

Fig. 17: Stress state in the L1T9 beams before failure 
Table 1: CFRP box beams tested in an experimental program

\begin{tabular}{cccccc}
\hline \hline \multirow{2}{*}{$\begin{array}{c}\text { EFRP type } \\
\end{array}$} & $\mathrm{M} / \mathrm{P}^{*}=\infty$ & \multicolumn{4}{c}{ Concrete-filled } \\
\cline { 3 - 6 } & 1 & $\mathrm{M} / \mathrm{P}=\infty$ & $\mathrm{M} / \mathrm{P}=0.32$ & $\mathrm{M} / \mathrm{P}=0.16$ & $\mathrm{M} / \mathrm{P}=0.04$ \\
\hline L9T1 & 1 & 1 & 1 & 1 & 1 \\
\hline L2T1 & 1 & 1 & 1 & 1 & 1 \\
\hline L1T1 & 1 & 1 & 1 & 1 \\
\hline L1T2 & 1 & 1 & 1 & 1 \\
\hline L1T9 & 1 & 1 & \\
\hline${ }^{*} \mathrm{M}=$ mid span bending moment $(\mathrm{kN}-\mathrm{m}), \mathrm{P}=$ axial compressive force $(\mathrm{kN})$ &
\end{tabular}


Table 2: The input properties of concrete

\begin{tabular}{lr}
\hline \hline Properties & Value \\
\hline Modulus of Elasticity, MPa & 28480 \\
Poisson's ratio & 0.174 \\
Compressive strength, MPa & 31.7 \\
Tensile strength, MPa & 3.0 \\
Tension softening modulus, MPa & 614 \\
\hline \hline
\end{tabular}


Table 3: In-plane material properties of CFRP laminates

\begin{tabular}{ccccccc}
\hline \hline Property & Unit & L9T1 & L2T1 & L1T1 & L1T2 & L1T9 \\
\hline$\sigma_{1}^{T *}$ & $\mathrm{MPa}$ & 1790 & 1759 & 1759 & 1759 & 1790 \\
\hline$\sigma_{1}^{C !}$ & $\mathrm{MPa}$ & -515 & -511 & -544 & -511 & -515 \\
\hline$\sigma_{2}^{T *}$ & $\mathrm{MPa}$ & 295 & 715 & 1759 & 715 & 295 \\
\hline$\sigma_{2}^{C}{ }^{*}$ & $\mathrm{MPa}$ & -173 & -247 & -544 & -247 & -173 \\
\hline$\tau_{12}^{F}{ }^{*}$ & $\mathrm{MPa}$ & 72 & 72 & 72 & 72 & 72 \\
\hline$E_{1}{ }^{*}$ & $\mathrm{MPa}$ & 110800 & 92300 & 92300 & 92300 & 110800 \\
\hline$E_{2}{ }^{*}$ & $\mathrm{MPa}$ & 20900 & 39000 & 92300 & 39000 & 20900 \\
\hline$G_{12}{ }^{*}$ & $\mathrm{MPa}$ & 3500 & 3530 & 3560 & 3530 & 3500 \\
\hline$\mu_{12}{ }^{*}$ & - & 0.13 & 0.10 & 0.08 & 0.10 & 0.13 \\
\hline * box coupon test; $\quad$ sheet coupon test; ${ }^{\dagger}$ Mallick (1993) & & & \\
\hline \hline
\end{tabular}


Table 4: Out-of-plane material properties for CFRP laminates

\begin{tabular}{ccccccc}
\hline \hline Property & Unit & L9T1 & L2T1 & L1T1 & L1T2 & L1T9 \\
\hline$\sigma_{3}^{T}$ & $\mathrm{MPa}$ & 62 & 62 & 62 & 62 & 62 \\
\hline$\sigma_{3}^{C *}$ & $\mathrm{MPa}$ & -173 & -173 & -173 & -173 & -173 \\
\hline$\tau_{23}^{F * *}$ & $\mathrm{MPa}$ & 32 & 32 & 32 & 32 & 32 \\
\hline$\tau_{13}^{F * *}$ & $\mathrm{MPa}$ & 32 & 32 & 32 & 32 & 32 \\
\hline$E_{3}{ }^{*}$ & $\mathrm{MPa}$ & 8500 & 8500 & 8500 & 8500 & 8500 \\
\hline$G_{23}{ }^{* !}$ & $\mathrm{MPa}$ & 3200 & 3200 & 3200 & 3200 & 3200 \\
\hline$G_{13}{ }^{* !}$ & $\mathrm{MPa}$ & 3200 & 3200 & 3200 & 3200 & 3200 \\
\hline$\mu_{23}{ }^{\dagger}$ & - & 0.460 & 0.464 & 0.465 & 0.464 & 0.460 \\
\hline$\mu_{13}{ }^{\dagger}$ & - & 0.432 & 0.462 & 0.465 & 0.462 & 0.432 \\
\hline
\end{tabular}

${ }^{*}$ Minimum of $\sigma_{2}^{C},{ }^{* *} 1 \%$ of corresponding shear modulus, ! (Toray 2007),

!! (Hyer 1998), ' Calculated from classical lamination theory 


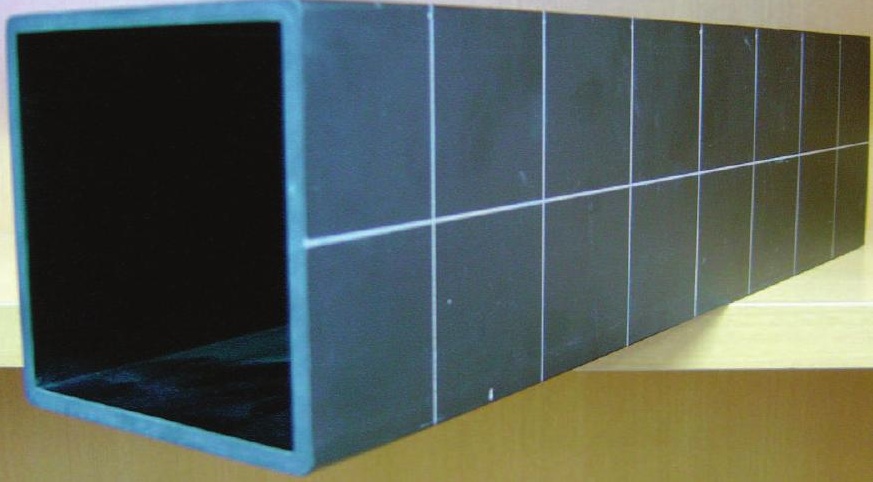



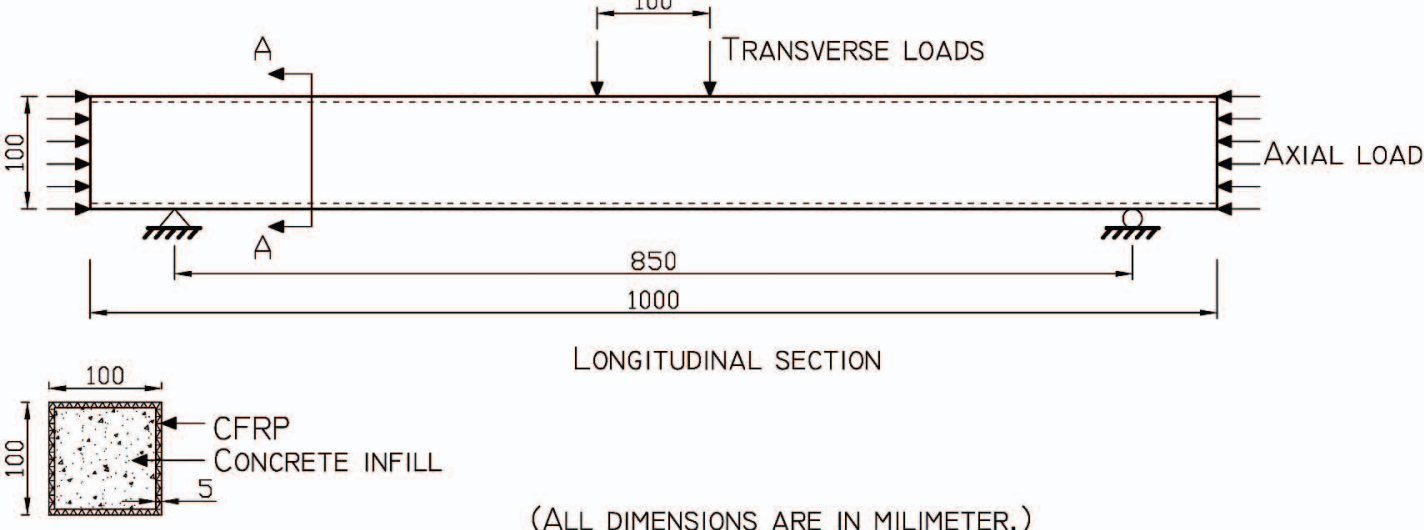

CROSS SECTION A-A

(ALL DIMENSIONS ARE IN MILIMETER.) 

105

100

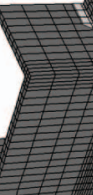




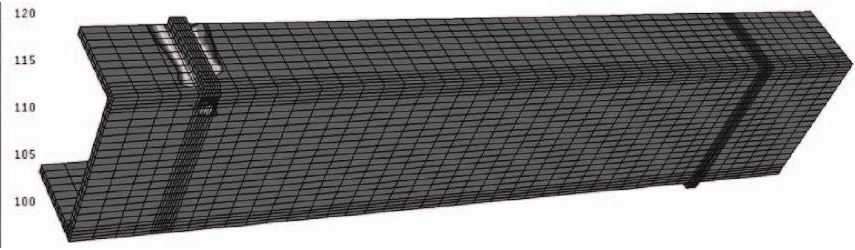




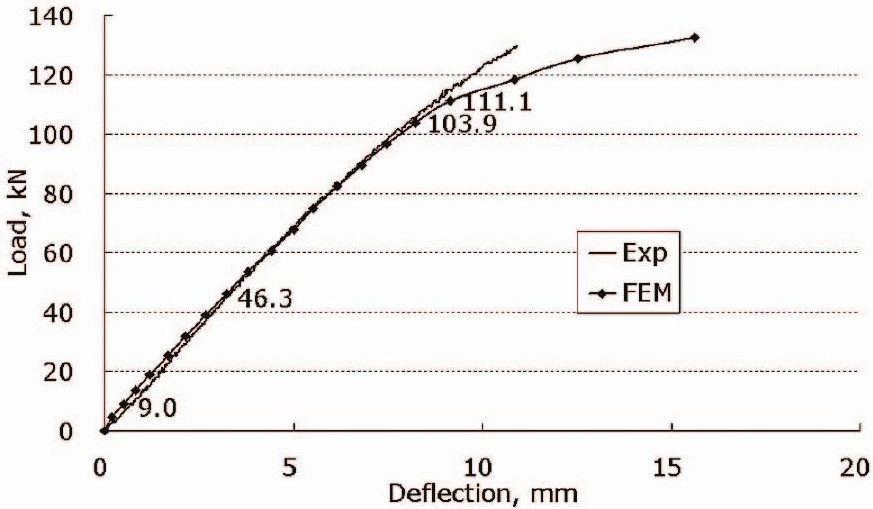




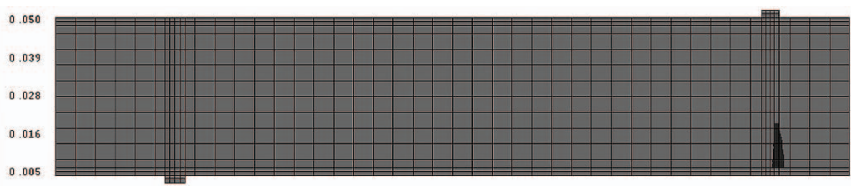


$H_{\text {oum }}$

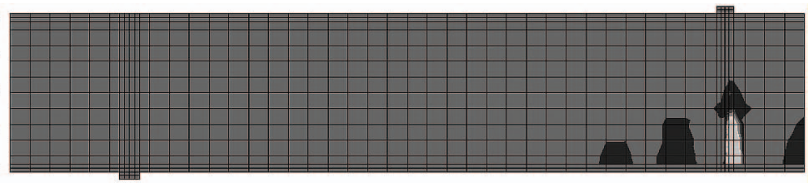


$\mid-0.002$

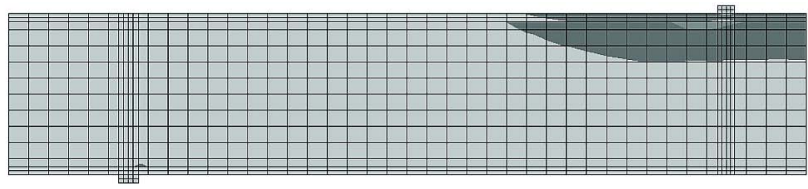

$-0.011$

$-0.016$ 


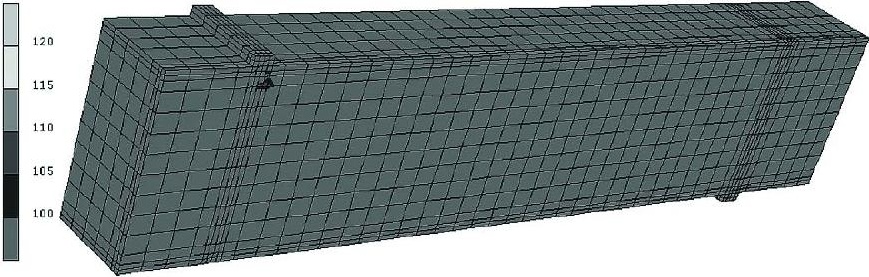




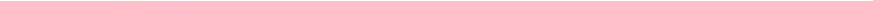


115

110

105

100
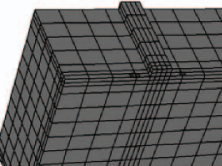

7

If 
115

110

105

100

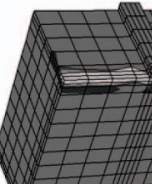


Longitudinal compressive stress, MPa

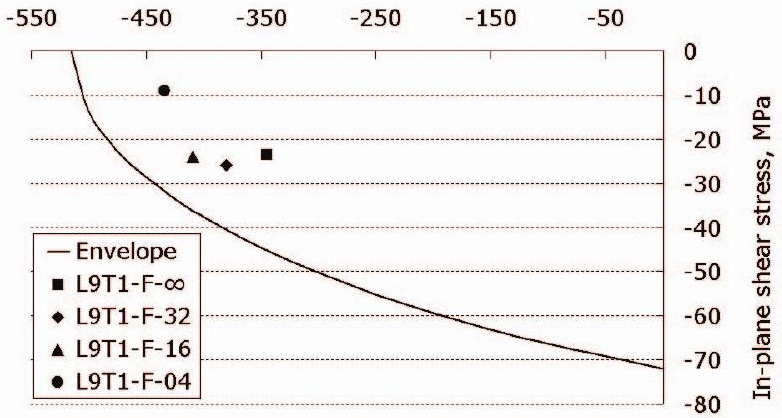


Longitudinal compressive stress, MPa

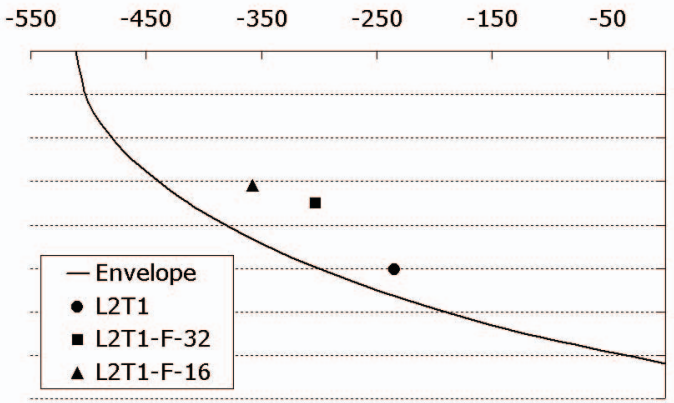

0 $-10 \sum$ -20 है -30 竞 $-40$ $-50 \frac{\Phi}{n}$ $\begin{array}{ll}-60 & \frac{1}{\frac{\pi}{0}} \\ -70 & \frac{1}{\frac{1}{1}}\end{array}$ $-80$ 
Longitudinal compressive stress, MPa

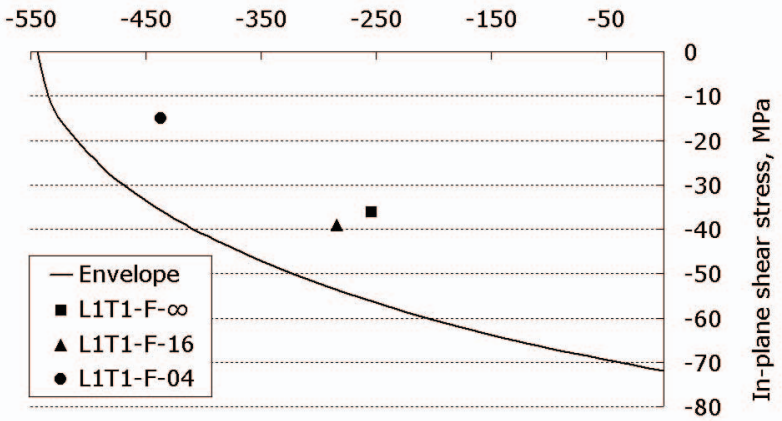


$-3.000 e+001$

$-4.000 e+001$

$-5.000 e+001$

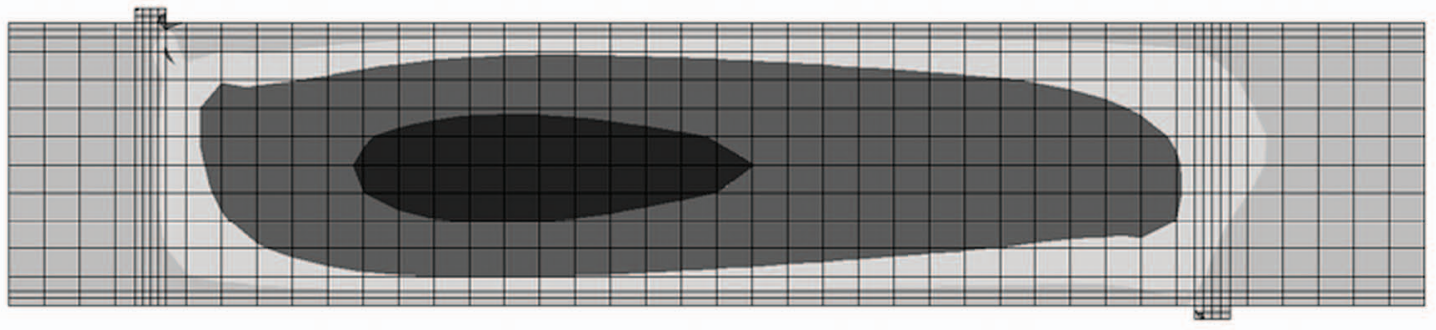


Longitudinal compressive stress, MPa

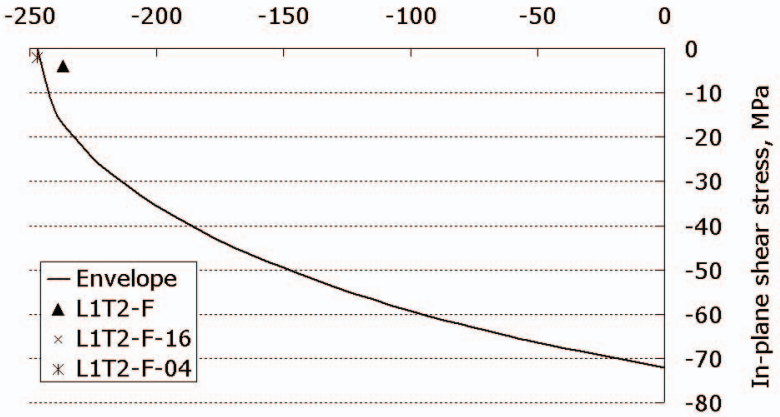




\section{Longitudinal compressive stress, MPa}
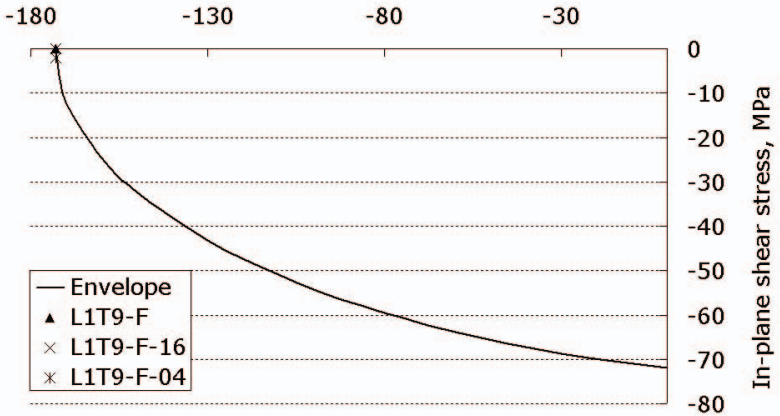